\title{
Critical Quality Attributes and Pharmaceutical Equivalence Assessment of Allopurinol Tablets in Argentina
}

María A. Varillas ${ }^{1}$, Marta I.V. Brevedan ${ }^{1}$, and Noelia L. Gonzalez Vidal1,2*

${ }^{1}$ Departamento de Biología, Bioquímica y Farmacia, Universidad Nacional del Sur (UNS), San Juan, Bahía Blanca, Argentina. ${ }^{2}$ CONICET, Argentina.

e-mail: nlgvidal@uns.edu.ar

\section{ABSTRACT}

Dissolution studies have evolved from a simple quality control test to an indicator of biopharmaceutical performance and alternative for in vivo equivalence and interchangeability assessment. Pharmaceutical equivalents imply products formulated with the same active pharmaceutical ingredient (API), in the same quantity and dosage form, that are intended to be administered by the same route fulfill the same quality criteria. The medicine market in Argentina is composed mostly of multisource products that are supposed to be pharmaceutical equivalents, but the generic market here is different from other parts of the world. In this scenario, the comparison of different products formulated with the same API becomes essential. Allopurinol, the drug of choice in the treatment of gout and tumor lysis syndrome, is classified as an essential medicine according to the World Health Organization. The present work aimed to compare critical quality attributes and in vitro dissolution characteristics of Allopurinol tablets purchased in Argentina to establish pharmaceutical equivalence. All evaluated products fulfilled the pharmaceutical equivalence criteria. Three of the tested products (the reference and two multisource formulations) comply with the criteria for 'very rapidly dissolving' and can be described as similar.

KEYWORDS: Allopurinol, Biopharmaceutical Classification System, dissolution profiles, pharmaceutical equivalence

\section{INTRODUCTION}

A llopurinol (ALLO) is a urate-lowering active pharmaceutical ingredient (API) that acts by decreasing the formation of uric acid through the inhibition of xanthine oxidase and is included in the World Health Organization (WHO) List of Essential Medicines (1). The drug was first approved by the United States Food and Drug Administration (US FDA) in 1966, and is currently used worldwide for the treatment of gout, gouty arthritis, uric acid stones, or hyperuricemia due to cancer or chemotherapy $(2,3)$. In fact, the development of ALLO was one of the most important advances in the treatment of hyperuricemia, an effort that was awarded with the 1988 Nobel Prize in medicine $(4,5)$.

ALLO presents a solubility value in water and $25^{\circ} \mathrm{C}$ of 0.48 $\mathrm{mg} / \mathrm{mL}$. (6). This API is presented in the pharmaceutical market at two dosage strengths, 100 and $300 \mathrm{mg}$. The 100-mg formulation is one example of APIs now included in the class 1 of the Biopharmaceutics Classification System (BCS) (7). Before the change in WHO regulations, where the permeability criterion was relaxed from the
FDA value of $90 \%$ to $85 \%$ to consider an API as 'highly permeable', the ALLO classification included mostly BCS class 3 , and eventually a class 4 case (8-10). Classification of the 300-mg formulation of ALLO is not straightforward, but the FDA clearly indicates that ALLO $300 \mathrm{mg}$ belongs to class IV (11).

In Argentina, ALLO tablets are available both as a reference and multisource product. In the Argentinean pharmaceutical market, it is a common practice for patients to replace the reference with multisource products, and even between the latter ones, based on economic reasons. Even though treatments could become more effective if patients were provided with proper knowledge to comprehend their care, it is important to point out that multisource products must have proven pharmaceutical equivalence. To establish that products containing the same API are pharmaceutical equivalents (i.e., same quantity, dosage form, and route of administration), it must be verified that they all comply with comparable critical quality standards $(12,13)$. Furthermore, in vitro dissolution studies can 
be applied to obtain useful information concerning the biopharmaceutical performance of the products. In this sense, dissolution profiles can be obtained in dissolution media of biological relevance, such as aqueous buffer solutions with $\mathrm{pH}$ values in the physiological range. In the case of APIs belonging to BCS class 1 and 3 , this procedure corresponds to similarity studies (for biowaivers), which are used to assess interchangeability of formulations in lieu of in vivo studies, under recommendations of national and international regulatory agencies (13-17). In the case of APIs outside this classification, the assessment of dissolution behavior in media of physiological relevance completes the critical evaluation of pharmaceutical equivalence and assures the availability of essential drugs of proven quality, safety, and efficacy at affordable prices.

To the best of our knowledge, only one study has been published in the literature comparing different ALLO products, and there are no studies regarding products marketed in Argentina (18). Therefore, the aim of the present study was to assess critical quality attributes and pharmaceutical equivalence of five commercial products containing ALLO (300 mg), marketed in Argentina, with focus on their biopharmaceutical performance.

\section{MATERIALS AND METHODS}

\section{Materials}

ALLO was acquired from Saporiti (Parafarm, Argentina). Distilled water was used for assay and preparation of dissolution media. Analytical grade chemicals were used for the same purpose, namely sodium hydroxide $(\mathrm{NaOH})$, hydrochloric acid $(\mathrm{HCl})$, glacial acetic acid, potassium chloride, sodium acetate trihydrate and monobasic potassium phosphate (ANEDRA, Argentina). Aqueous buffer solutions $(\mathrm{pH} 1.2 \mathrm{HCl}, \mathrm{pH} 4.5$ acetate, and pH 6.8 phosphate), used as dissolution media of physiological significance, were prepared in compliance with the United States Pharmacopeia (USP) (19).

Five different ALLO tablets (labeled amount: $300 \mathrm{mg}$ ) were purchased in local pharmacies of the Argentine market. Tablets were arbitrarily labeled from $A$ to $E$, with sample $D$ being the reference product, and the other formulations being multisource products. The composition of the evaluated formulations is presented in Table 1. All tests were performed within the shelf life of the products.

The information present in labels (primary and secondary packaging) and patient leaflets was evaluated and compared to verify compliance with local legislation $(20,21)$.
Table 1. Qualitative Composition of Excipients in Allopurinol Formulations

\begin{tabular}{|c|c|c|c|c|c|c|}
\hline $\begin{array}{l}\text { Excipient } \\
\text { type }\end{array}$ & Excipient & $A^{b}$ & B & $\mathrm{C}^{\mathrm{c}}$ & $\begin{array}{c}\text { D } \\
\text { (Ref.) }\end{array}$ & $\overline{E^{c}}$ \\
\hline \multirow[t]{2}{*}{ Filler/Diluent } & Lactose & & - & + & + & - \\
\hline & $\begin{array}{l}\text { Microcrystalline } \\
\text { Cellulose }^{a}\end{array}$ & & + & - & - & + \\
\hline \multirow[t]{7}{*}{ Disintegrant } & Corn Starch ${ }^{\mathrm{a}}$ & & - & + & + & - \\
\hline & Povidone $^{a}$ & & + & + & + & + \\
\hline & Crospovidone & & - & - & - & - \\
\hline & $\begin{array}{l}\text { Croscarmellose } \\
\text { sodium }\end{array}$ & & - & + & + & + \\
\hline & Docusate Sodiuma & & - & - & - & - \\
\hline & $\begin{array}{l}\text { Sodium Starch } \\
\text { Glycolate }\end{array}$ & & + & - & - & - \\
\hline & $\begin{array}{l}\text { Pregelatinized } \\
\text { starch }^{a}\end{array}$ & & - & - & + & - \\
\hline \multirow[t]{3}{*}{ Glidant } & $\begin{array}{l}\text { Sodium Lauryl } \\
\text { Sulphate }^{\mathrm{a}}\end{array}$ & & - & - & - & - \\
\hline & $\begin{array}{l}\text { Colloidal Silicon } \\
\text { Dioxide }\end{array}$ & & + & - & + & + \\
\hline & Talc $^{\mathrm{a}}$ & & - & - & - & - \\
\hline \multirow[t]{2}{*}{ Lubricant } & $\begin{array}{l}\text { Magnesium } \\
\text { Stearate }\end{array}$ & & + & + & + & + \\
\hline & Polyethylene Glycol & & - & - & - & + \\
\hline \multicolumn{7}{|c|}{$\begin{array}{l}{ }^{a} \text { This excipient has multiple functions. } \\
{ }^{b} \text { Label and/or leaflet do not inform qualitative composition of excipients. } \\
\text { 'Label and/or leaflet inform qualitative and quantitative composition of } \\
\text { excipients. } \\
+ \text { indicates presence and - indicates absence of excipient. }\end{array}$} \\
\hline
\end{tabular}

\section{Equipment}

A Varian Cary 50 Conc Spectrophotometer (Varian Instruments, Australia) was used for assay and quantification of API in dissolution studies. Hardness, friability, and disintegration of the tablets were measured using a Scout DGMO2, FGMO2, and EGMO2, respectively (Scout Electronics, Argentina). In vitro dissolution studies were performed with an Erweka DT60 (Erweka GmbH, Germany). An Acculab ALC-210.4M (Acculab, USA) electronic analytical balance was used to weigh materials and tablets.

\section{Evaluation of Critical Quality Attributes}

For weight variation analysis, 10 randomly chosen tablets from each commercial sample were individually weighed, and the mean value and corresponding standard deviation (SD) were calculated.

Friability, hardness, and disintegration tests were completed according to Argentine Pharmacopeia (20). 
Ten tablets from each sample were weighed and placed into the friability tester. After 100 revolutions $(25 \mathrm{rpm}$ for $4 \mathrm{~min})$, the tablets were removed from the tester and weighed, and the result was compared with the initial weight value (20). The hardness of 10 individual tablets of each sample was measured in terms of the degree of force in kilopounds $(\mathrm{kp})$ required to break each tablet across the diameter. The disintegration time of tablets ( $n=6$, for each sample) was assessed at $37.0 \pm 2.0^{\circ} \mathrm{C}$ in distilled water for 30 minutes. Unless otherwise specified in the corresponding monograph, it should be observed that all tablets completely disintegrate in the indicated testing time (20).

For the assay test, 20 tablets were randomly selected, weighed, and finely powdered. An exactly weighed quantity of powder, containing approximately $100 \mathrm{mg}$ of ALLO, was dissolved using $0.05 \mathrm{M} \mathrm{NaOH}$. The obtained solution was filtered through a $0.45-\mu \mathrm{m}$ pore-size nylon membrane (Gamafil, Argentina) and suitably diluted with $0.1 \mathrm{M} \mathrm{HCl}$. ALLO concentration was determined by UVspectrophotometry at $250 \mathrm{~nm}$ (applying the standard calibration curve developed for this purpose: $y=0.0576$ $x-0.0096 ; r^{2}=0.9998$; concentration range 4.0-14.0 $\mu \mathrm{g} /$ $\mathrm{mL})(22,23)$. This same methodology was individually applied to 10 tablets of each commercial sample for assessment of uniformity of dosage units.

Dissolution tests were performed using a calibrated USP apparatus 2 at $75 \mathrm{rpm}$ with $900 \mathrm{~mL}$ of $0.01 \mathrm{~N} \mathrm{HCl}$ at 37.0 $\pm 0.5^{\circ} \mathrm{C}$ as dissolution medium $(19,20)$. Six replicates ( $n$ $=6$ ) of each product were evaluated for stage 1 (S1) of dissolution acceptance criteria. Samples were withdrawn at the time specified in the corresponding monograph (45 $\mathrm{min}$ ), filtered through a $0.45-\mu \mathrm{m}$ pore-size nylon membrane (Gamafil), and suitably diluted with the same medium. Drug concentration was determined by spectrophotometric analysis at $250 \mathrm{~nm}$ (applying the following calibration curve: $y=0.0584 x-0.0249 ; r^{2}=$ 0.9997). Argentine Pharmacopeia states that not less than $75 \%(Q)$ of the labeled amount of ALLO should be dissolved within 45 minutes (20).

\section{Biopharmaceutical Performance of ALLO tablets}

To evaluate the biopharmaceutical performance of the selected products, dissolution profiles ( $n=12$ for

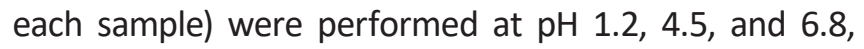
applying the same experimental conditions of the dissolution quality control test (as stated above). Samples $(10 \mathrm{~mL})$ were withdrawn at $5,10,15,20,30$, 45 , and 60 minutes (with replacement of fresh medium) and subsequently filtered, diluted, and measured by
UV analysis. The concentration in each sample was calculated from calibration curves constructed in each dissolution medium ( $r^{2}$ range: 0.9973-0.9994). Cumulative percentages of dissolved API were calculated for dissolution profile assessment, where each point of the dissolution profile corresponds to the mean value and its respective SD.

\section{Statistical Analysis}

Dissolution profiles were characterized in terms of the model independent parameter dissolution efficiency (DE) (24). DE values were statistically evaluated applying analysis of variance (ANOVA) followed by least significant difference (LSD). Mathematical comparison of dissolution profiles was carried out in terms of similarity factor, $f_{2}$ (13-17). Statistical analysis was performed using InfoStat software, version 2014 (http://www.infostat.com.ar).

\section{RESULTS AND DISCUSSION}

Not all the evaluated products could be considered equivalent with respect to the information provided about storage conditions (Table 2). Argentine Pharmacopeia states that the correct storage conditions should be "to preserve in well-closed containers," and this should be indicated both in the secondary packaging and patient leaflet (20). None of the samples indicated the requirement of "well-closed" packaging, although sample $C$ indicated keeping the tablets in their original container. All samples referred to conditions of appropriate storage, and almost all presented an upper limit of 30 ${ }^{\circ} \mathrm{C}$. Concerning the general information provided by the manufacturers, it is important to highlight that sample A did not provide information about the composition of excipients (qualitative not quantitative ) (Table 1), which is a requirement of local legislation (21). Another issue is the important differences in the prices of evaluated ALLO products, with sample $\mathrm{E}$ having the highest cost, $62.5 \%$ higher than the most economic one (sample A) (Table 2). This is an important factor to be considered because interchangeability decisions by patients in Argentina are generally based on economic reasons.

\section{Critical Quality Attributes}

The results of physical tests are shown in Table 2. Large differences were detected between the weight values of different samples, with mean results ranging from 432.0 to $720.2 \mathrm{mg}$. Differences in composition, typical of each manufacturer (and presented in Table 1), and different physical dimensions of each product could explain this range of results, without necessarily involving variations in the API content or dissolution performance. With respect to hardness evaluation, the mean results 
Table 2. Information of Evaluated Products and Results of Physical Quality Control Tests for Allopurinol Formulations

\begin{tabular}{|c|c|c|c|c|c|c|}
\hline Sample & Price $^{a}$ & Storage Conditions ${ }^{b}$ & $\begin{array}{l}\text { Tablet Weight } \\
(\mathrm{mg})^{c}\end{array}$ & Hardness $(k p)^{c}$ & $\begin{array}{l}\text { Friability (\% of } \\
\text { Weight Loss) }\end{array}$ & $\begin{array}{l}\text { Disintegration } \\
\text { Time }^{d}\end{array}$ \\
\hline A & 3.46 & Store between 15 and $30^{\circ} \mathrm{C}$ & $432.0 \pm 5.0$ & $9.7 \pm 0.5$ & 0.41 & $51 \mathrm{~s}$ \\
\hline B & 4.86 & $\begin{array}{l}\text { Store at a room temperature } \\
\text { (pref. between } 15 \text { and } 30^{\circ} \mathrm{C} \text { ). }\end{array}$ & $451.3 \pm 3.7$ & $7.5 \pm 0.3$ & 0.29 & $2 \min 36 s$ \\
\hline C & 5.30 & $\begin{array}{l}\text { Store at a room temperature } \\
\text { between } 15 \text { and } 30^{\circ} \mathrm{C} \text {, in its } \\
\text { original case and protected } \\
\text { from light and heat. }\end{array}$ & $695.7 \pm 3.0$ & $11.6 \pm 0.5$ & 0.04 & $5 \min 36 s$ \\
\hline D (Ref.) & 5.34 & $\begin{array}{l}\text { Store in original case at room } \\
\text { temperature and dry place. }\end{array}$ & $708.9 \pm 7.0$ & $15.8 \pm 1.0$ & 0.05 & $5 \min 11 \mathrm{~s}$ \\
\hline E & 5.62 & $\begin{array}{l}\text { Store at room temperature } \\
\text { below } 30^{\circ} \mathrm{C} .\end{array}$ & $720.2 \pm 7.0$ & $34.3 \pm 0.1$ & 0.04 & $5 \min 42 \mathrm{~s}$ \\
\hline
\end{tabular}

aprice per tablet in argentine pesos at the time of analysis.

'Information presented in labels and leaflets.

${ }^{c}$ Mean value \pm standard deviation.

${ }^{d}$ Maximum time needed for complete disintegration of evaluated tablets.

ranged from 7.5 to $34.3 \mathrm{kp}$, which could be considered an acceptable range. In the case of friability tests, the pharmacopeial specification states that 'a maximum mean weight loss of not more than $1.0 \%$ is considered acceptable' $(19,20)$. All evaluated samples fulfilled this requirement, as shown in Table 2. For disintegration assessment, the pharmacopeial specification states that 'at the end of the time limit specified in the monograph all of the tablets have disintegrated completely' $(19,20)$. All evaluated products showed acceptable disintegration times, with results ranging between 51 seconds and almost 6 minutes (Table 2). Therefore, all samples met the official compendium requirement of 30-minute disintegration time (20). It is important to point out that the hardest formulation (sample E) also exhibits the lowest weight loss in friability determination and the longest disintegration time (Table 2). Nevertheless, no apparent relationship could be found, because the sample with the lowest hardness value (sample B) had an intermediate result for friability and disintegration time, and samples with similar friability and disintegration time (samples E and C) differed in hardness results (Table 2).

ALLO tablets should contain an amount equivalent to 93.0-107.0\% of the labeled amount of ALLO, as indicated in the respective monograph (20). As shown in Table 3, assay results for all evaluated products fulfilled these requirements, with results that ranged from $97.8 \pm 2.6$ (sample A) to $103.7 \pm 2.1$ (sample E). On the other hand, the specifications for uniformity indicate that API content should be between $85.0-115.0 \%$ of the labeled amount in each evaluated dosage unit, and the relative standard deviation (RSD) should not exceed $6.0 \%$ (20). All evaluated products fulfilled these requirements.

The ALLO tablets monograph includes specifications for in vitro dissolution testing, stating that 'not less than $75 \%$ (Q) of the labeled amount of ALLO is dissolved in 45 minutes' (20). According to the results shown in Table 3, all formulations complied with specification for the S1 dissolution test.

Table 3. Assay, Uniformity of Dosage Units, and Dissolution Test Results for Allopurinol Formulations

\begin{tabular}{|c|c|c|c|}
\hline \multirow{2}{*}{ Sample } & Assay $^{\mathrm{a}}$ & $\begin{array}{c}\text { Uniformity of } \\
\text { Dosage Units }^{\mathrm{b}}\end{array}$ & $\begin{array}{c}\text { Dissolution Test } \\
\text { (S1 Stage) }^{\mathrm{c}}\end{array}$ \\
\cline { 2 - 4 } & $93.0-107.0 \%$ & $\begin{array}{c}\mathbf{8 5 . 0}-115.0 \% ; \\
\text { RSD }<6.0 \%\end{array}$ & $\mathbf{7 5 \% ( Q ) \text { in 45 min }}$ \\
\hline A & $97.8 \pm 2.6$ & $95.9-100.0 / 1.2$ & $88-92 / 1.8$ \\
\hline B & $101.5 \pm 2.9$ & $100.5-102.8 / 0.8$ & $89-92 / 1.7$ \\
\hline C & $99.2 \pm 2.0$ & $98.8-100.3 / 0.5$ & $90-95 / 2.4$ \\
\hline D (Ref.) & $102.1 \pm 2.8$ & $100.3-104.2 / 1.2$ & $101-105 / 2.0$ \\
\hline E & $103.7 \pm 2.1$ & $102.5-105.7 / 1.0$ & $100-102 / 1.1$ \\
\hline
\end{tabular}

${ }^{a}$ Percentage of labeled amount. Mean value $\pm S D$.

${ }^{b}$ Range of \% labeled amount / RSD.

'Range of \% labeled amount dissolved /RSD. S1 Stage corresponds to the first (of three) instance of approval for in vitro dissolution test according to the acceptance table for "Dissolution" chapter in United States Pharmacopeia.

RSD: relative standard deviation; Q: amount of dissolved active pharmaceutical ingredient, specified in the individual monograph, expressed as a percentage of labeled content of the dosage unit.

\section{Biopharmaceutical Performance}

Dissolution profiles obtained in physiologically relevant media are presented in Figures 1-3. The reference formulation (D) and the samples $B$ and $E$ are considered 


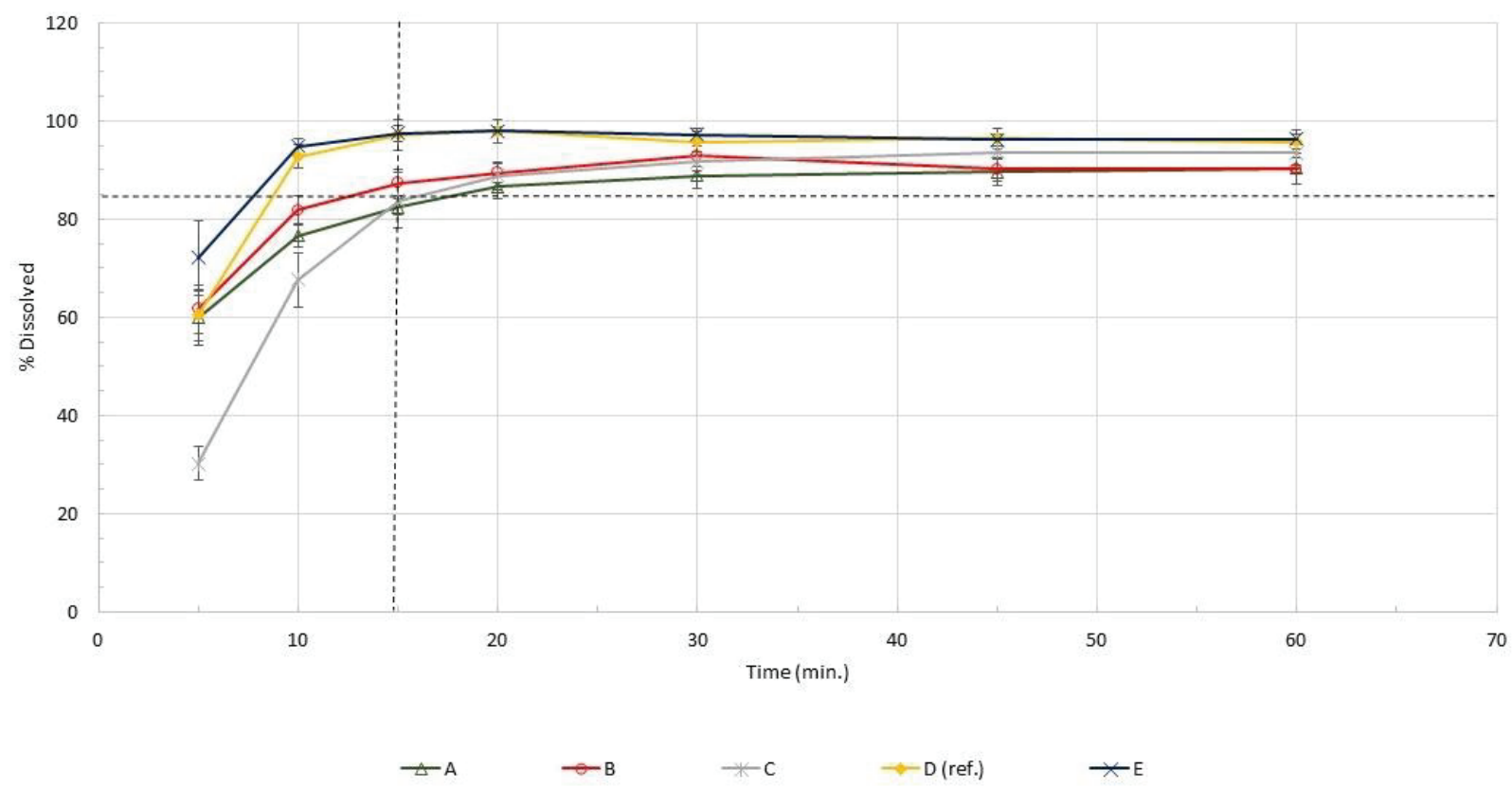

Figure 1. Dissolution profiles for Allopurinol formulations in hydrochloric buffer solution (pH 1.2). Each point of the profile represents the mean result for the percentage of ALLO labeled amount dissolved, at each sampling time, and the corresponding error bars (standard deviation). Dotted lines represent the 'very rapidly dissolving' limits (85\% dissolved at 15 minutes).



Figure 2. Dissolution profiles for Allopurinol formulations in acetic buffer solution ( $\mathrm{pH}$ 4.5). Each point of the profile represents the mean result for the percentage of ALLO labeled amount dissolved, at each sampling time, and the corresponding error bars (standard deviation). Dotted lines represent the 'very rapidly dissolving' limits (85\% dissolved at 15 minutes). 


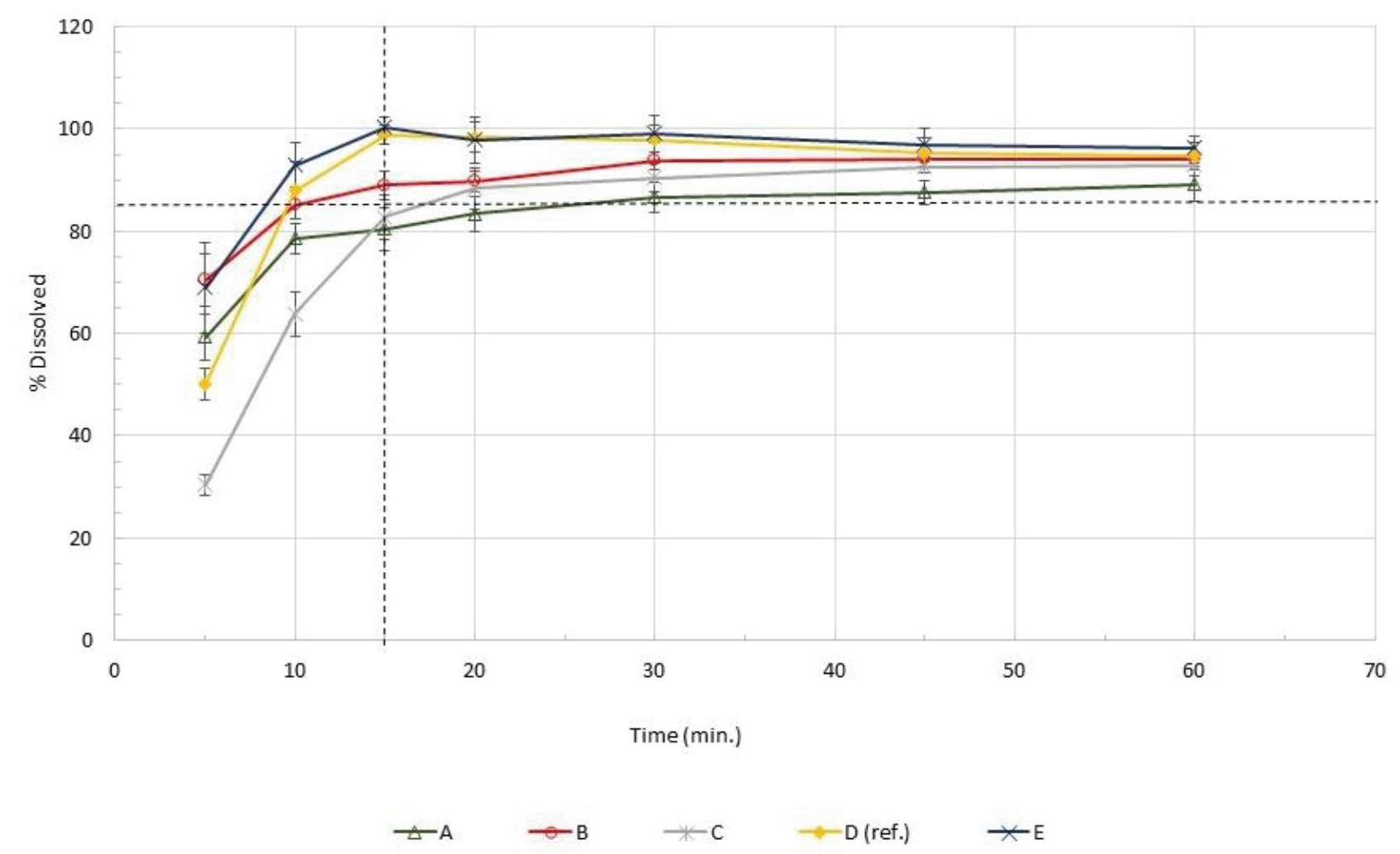

Figure 3. Dissolution profiles for Allopurinol formulations in phosphate buffer solution (pH 6.8). Each point of the profile represents the mean result for the percentage of ALLO labeled amount dissolved, at each sampling time, and the corresponding error bars (standard deviation). Dotted lines represent the 'very rapidly dissolving' limits (85\% dissolved at 15 minutes).

as 'very rapidly dissolving' (i.e., $85 \%$ dissolved in the first 15 minutes). On the other hand, DE results could be considered satisfactory, because values were greater than $77.0 \%$ for all samples and all media, with the highest values registered for samples $D$ and $E$ (Table 4). The statistical comparison of these results (by ANOVA) revealed the existence of significant differences in $D E$ results for samples $A$ and $C$, with respect to the reference formulation, in all media (Table 4). In the case of sample $\mathrm{B}$, significant differences were detected in $\mathrm{pH} 1.2$ and 4.5 buffer solutions, but not in phosphate buffer (Table 4). Finally, for sample $E$ no statistical differences were detected when compared to reference formulation, in all media (Table 4). Dissolution profiles were also compared using the similarity factor, $f_{2}$. Even though $300-\mathrm{mg}$ ALLO is considered a BCS class IV drug, the application of $f 2$ could be useful to completely characterize and compare dissolution profiles. In this sense, considering that both samples $B$ and $E$, as well as the reference product $D$, are 'very rapidly dissolving' formulations, the mathematical evaluation is considered not necessary because the profiles would be essentially similar (13-17). In the case of samples $\mathrm{A}$ and $\mathrm{C}, f_{2}$ was calculated prior to verification that all requirements for its application were fulfilled (1317). In the comparison of sample $A$ with the reference formulation, the obtained $f_{2}$ results were $45.4,46.8$, and 44.0 for buffer $\mathrm{pH} 1.2,4.5$, and 6.8 , respectively. In the case of comparison of sample $\mathrm{C}$ with the reference product D, the results were 33.6, 34.4, and 36.9, respectively. All obtained similarity factors were lower than the limit value of 50 , suggesting that these profiles could not be considered similar, which is in accordance with the ANOVA results (13-17).

\section{CONCLUSION}

Allevaluated productsfulfilled Argentinean Pharmacopeial specifications for critical quality attributes under the experimental conditions employed. These results demonstrate that the 300-mg ALLO products tested from the local market are pharmaceutical equivalents. Nevertheless, caution must be critically exerted, especially with products $A$ and $C$, considering that patients may interchange multisource products for economic reasons, regardless of biopharmaceutical performance. 
Table 4. Dissolution Efficiency Results for Allopurinol Formulations

\begin{tabular}{|c|c|c|c|c|c|}
\hline Medium & A & B & C & D (Ref.) & E \\
\hline pH 1.2 & $81.3 \pm 2.0^{*}$ & $83.6 \pm 2.0^{*}$ & $80.5 \pm 1.9^{*}$ & $89.1 \pm 1.0$ & $90.6 \pm 0.9$ \\
\hline pH 4.5 & $80.2 \pm 1.9^{*}$ & $83.3 \pm 1.0^{*}$ & $77.0 \pm 1.5^{*}$ & $88.8 \pm 1.4$ & $86.6 \pm 1.1$ \\
\hline pH 6.8 & $79.7 \pm 2.6^{*}$ & $86.5 \pm 1.1$ & $79.4 \pm 1.6^{*}$ & $88.1 \pm 2.1$ & $91.0 \pm 2.0$ \\
\hline
\end{tabular}

Results are expressed in \% of labelled amount dissolved (mean \pm standard deviation).

* indicates significant differences $(p \leq 0.05)$ detected, with respect to the reference formulation $D$.

\section{FUNDING}

This work was supported by Universidad Nacional del Sur (PGI 24/ZB70).

\section{DECLARATIONS OF INTEREST}

The authors disclosed no conflicts of interest related to this article.

\section{REFERENCES}

1. WHO Model List of Essential Medicines, 20th List. World Health Organization: Geneva, Switzerland, August 2017.

2. Burns, C. M.; Wortmann, R. L. Latest evidence on gout management: what the clinician needs to know. Ther. Adv. Chronic Dis. 2012, 3, 271-286. DOI: 10.1177/2040622312462056.

3. Fleeman, N.; Pilkington, G.; Dundar, Y.; Dwan, K.; Boland, A.; Dickson, R.; Anijeet, H.; Kennedy, T.; Pyatt, J. Allopurinol for the treatment of chronic kidney disease: a systematic review. Health Technol. Assess. 2014, 18, 1-77, v-vi. DOI: 10.3310/hta18400.

4. Rundles, R. W.; Wyngaarden, J. B.; Hitchings, G. H.; Elion, G. B.; Silberman, H. R. Effects of a xanthine oxidase inhibitor on thiopurine metabolism, hyperuricemia and gout. Trans. Assoc. Am. Physicians. 1963, 76, 126-140.

5. Nuki, G.; Simkin, P. A. A concise history of gout and hyperuricemia and their treatment. Arthritis Res. Ther. 2006, 8, S1. DOI: 10.1186/ar1906.

6. Benezra, S. A.; Bennett T. R. Allopurinol. In: Analytical Profiles of Drug Substances; Florey, K., Ed.; Academic Press Inc.: California, 1978; . 7, 1-17.

7. WHO Expert Committee on Specifications for Pharmaceutical Preparations. Proposal to waive in vivo bioequivalence requirements for WHO Model List of Essential Medicines immediate-release solid oral dosage forms; WHO Technical Report Series, No. 937, Annex 8;. World Health Organization: Geneva, Switzerland, 2006; pp 391-437.

8. Takagi, T.; Ramachandran, C.; Bermejo, M.; Yamashita, S.; Yu, L. X.; Amidon, G. L. A provisional biopharmaceutical classification of the top 200 oral drug products in the United States, Great Britain,
Spain, and Japan. Mol. Pharm. 2006, 3, 631-643. DOI: 10.1021/mp0600182.

9. Kasim, N. A.; Whitehouse, M.; Ramachandran, C.; Bermejo, M.; Lennernäs, H.; Hussain, A. S.; Junginger, $H$. E.; Stavchansky, S. A.; Midha, K. K.; Shah, V. P.; Amidon G. L. Molecular Properties of WHO essential drugs and provisional Biopharmaceutical Classification. Mol. Pharm. 2004, 1, 85-96. DOI: 10.1021/mp034006h.

10. Lindenberg, M.; Kopp, S.; Dressman, J. B. Classification of orally administered drugs on the World Health Organization Model list of Essential Medicines according to the biopharmaceutics classification system. Eur. J. Pharm. Biopharm. 2004, 58, 265-278. DOI: 10.1016/j.ejpb.2004.03.001.

11. NDA 209203 Multi-disciplinary Review and Evaluation 505(b) (2) Duzallo (lesinurad/allopurinol). Center for Drug Evaluation and Research (CDER). US Food and Drug Administration, 2016.

12. Disposition 3185/99: Approval of the technical recommendations contained in the document "Schedule for requirements of equivalence studies between medicines of significant health risk." [in Spanish] Administración Nacional de Medicamentos, Alimentos y Tecnología Médica (ANMAT), 1999.

13. WHO Expert Committee on Specifications for Pharmaceutical Preparations. Multisource (generic) pharmaceutical products: guidelines on registration requirements to establish interchangeability; WHO Technical Report Series, No. 1003, Annex 6,. World Health Organization: Geneva, Switzerland, 2017; pp 181-236.

14. Guideline on the Investigation of Bioequivalence; CPMP/EWP/QWP/1401/98 Rev. 1; Committee for Medicinal Products for Human Use (CHMP). European Medicines Agency: London, 2010.

15. Waiver of In Vivo Bioavailability and Bioequivalence Studies for Immediate-Release Solid Oral Dosage Forms Based on a Biopharmaceutics Classification System; Guidance for Industry; U.S. Department of Health and Human Services, Food and Drug Administration, Center for Drug Evaluation and Research (CDER). U.S. Government Pringing Office: Washington, DC, 2017. 
16. Disposition 758/2009: Biowaiver criteria for Bioequivalence Studies of immediate-release solid oral dosage forms. [in Spanish] Administración Nacional de Medicamentos, Alimentos y Tecnología Médica (ANMAT), 2009.

17. Disposition 6766: Guidance for Biowaiver application of active pharmaceutical ingredients with bioequivalence requierement. [in Spanish] Administración Nacional de Medicamentos, Alimentos y Tecnología Médica (ANMAT), 2016.

18. Alghadi, R.Y.; Hamedelniel, E.I. Biowaiver studies of seven generic brands of allopurinol (100 mg) tablets available in Sudanese market. Saudi J. Med. Pharm. Sci. 2017, 3, 1230-1236. DOI: 10.21276/ sjmps.2017.3.11.16.

19. The United States Pharmacopeia and National Formulary USP 41-NF 36, The United States
Pharmacopeial Convention, Inc.: Rockville, MD, 2018.

20. Argentine Pharmacopeia, 7th Ed; Administración Nacional de Medicamentos, Alimentos y Tecnología Médica (ANMAT): Buenos Aires, Argentina, 2013.

21. Disposition ANMAT 5904/1996: Definitions and general guidelines on how the information should be included in the leaflets of pharmaceutical products whose condition of sale is under prescription. [in Spanish] Administración Nacional de Medicamentos, Alimentos y Tecnología Médica (ANMAT), 1996.

22. Japanese Pharmacopoeia, 17th ed.; Ministry of Health, Labour, and Welfare: Tokyo, Japan, 2016.

23. The British Pharmacopoeia. The Stationary Office: London, 2009.

24. Khan, K. A. The concept of dissolution efficiency. J. Pharm. Pharmacol. 1975, 27, 48-49. DOI: 10.1111/ j.2042-7158.1975.tb09378.x. 